\begin{tabular}{|c|l|}
\hline Title & 半凝固遠心鋳造法により作製したAI-Cr-Cu合金管の組織と耐摩耗性 \\
\hline Author(s) & 大参, 達也; 室田, 康宏; 工藤, 昌行 \\
\hline Citation & $\begin{array}{l}\text { 日本金属学会誌, 66(5), 537-542 } \\
\text { https://di.org/40.2320/1nstmet1952.66.5_537 }\end{array}$ \\
\hline Issue Date & 2002-05-01 \\
\hline Doc URL & http://hdl.handle.net/2115/74666 \\
\hline Type & article \\
\hline File Information & 1-2.pdf \\
\hline
\end{tabular}

Instructions for use 


\title{
半凝固遠心鋳造法により作製した $\mathrm{Al}-\mathrm{Cr}-\mathrm{Cu}$ 合金管の 組織と耐摩耗性
}

\section{大参達也室田康宏* 工藤昌行}

\author{
北海道大学大学院工学研究科
}

J. Japan Inst. Metals, Vol. 66, No. 5 (2002), pp. 537-542

(C) 2002 The Japan Institute of Metals

\section{Structure and Wear Resistance of Al-Cr-Cu Alloy Pipes Produced by a Semi-Solid Centrifugal Casting Process}

Tatsuya Ohmi, Yasuhiro Murota* and Masayuki Kudoh

Division of Materials Science and Engineering, Graduate School of Engineering, Hokkaido University, Sapporo 060-8628

The solidification structure, hardness and wear resistance of surface composite castings of an $\mathrm{Al}-\mathrm{Cr}-\mathrm{Cu}$ alloy produced by a two-step process of stir-mix-quenching and centrifugal casting have been investigated. In this process, two kinds of molten metals with different compositions are mixed with agitation in a mixing vessel to produce semi-solid slurry containing fine intermetallic crystals, and then the slurry is centrifugally cast. In the stir-mix-quenching experiments, a hypoeutectic $\mathrm{Al}-\mathrm{Cu}$ alloy melt was used for "the first melt" which acts as a coolant, and a hyperperitectic Al-Cr alloy melt with a higher liquidus temperature was used for "the second melt," which is rapidly quenched to precipitate numerous primary intermetallic crystals when it is brought into contact with the first melt.

The structure, hardness and wear resistance of the specimen vary with the mass fraction of $\alpha$-phase (aluminum solid solution) in the slurry. As the fraction of $\alpha$-phase increases, the volume of macroscopic pores and hardness of the composite layer decrease. On the other hand, the composite layer has good wear resistance when the slurry with proper amount of $\alpha$-phase was used. In such case, $\theta$-phase $\left(\mathrm{Al}_{2} \mathrm{Cu}\right)$ acts as an bonding material for the primary intermetallic crystals to form rigid network of hard phases.

(Received December 19, 2001; Accepted March 26, 2002)

Keywords: semi-solid processing, centrifugal casting, composite material, wear resistance, hardness, mixing, rapid solidification, aluminum alloy, intermetallic compound, structure control, solidification

\section{1. 緒言}

硬質の強化粒子によるアルミニウム合金の複合化は，硬さ や耐摩耗性の向上に有効である。その場合，必要な部位に必 要な量だけ強化粒子が存在するように，粒子の空間的分布を 制御できることが望ましい. その有力な手段の一つとして, 強化粒子を含んだスラリー状の合金溶湯を遠心鋳造する手 法 ${ }^{1-5)}$ が挙げられる. この手法では, スラリーに遠心力を作 用させ, 液体と粒子との密度差を利用して粒子の分布を偏在 化または傾斜化させる.

複合される強化粒子の種類としては, これまで, 炭化ケイ 素 $(\mathrm{SiC})^{1-3)}$, シラス $\left(\mathrm{Al}_{2} \mathrm{O}_{3}-\mathrm{SiO}_{2} \text { 系 }\right)^{4)}$ などのセラミックスや 金属間化合物 $\left.\mathrm{Al}_{3} \mathrm{Ti}^{5}\right)$ を使用した研究例が報告されている.

セラミックスの強化粒子を使用する場合は, アルミニウム 合金中に強化粒子を複合する工程が必要であるが，その操作 に伴う困難を回避するために，しばしば市販の複合材料が出

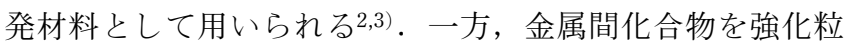
子とする例としては, 初晶 $\mathrm{Al}_{3} \mathrm{Ti}$ 粒子を含む過包晶 $\mathrm{Al}-\mathrm{Ti}$

\footnotetext{
* 北海道大学大学院生, 現在 : 日本鋼管 (Graduate Student, Hokkaido University, Present address: NKK Co., Ltd.)
}

合金を加熱して半溶融スラリーとし，これを遠心鋳造する手 法が検討された ${ }^{5)}$ 。この手法には，強化粒子を複合化する工 程が不要であるという利点がある.しかし，一般にアルミニ ウム合金から晶出する初晶金属間化合物は粗大に成長するこ とが多く，機械的強度や加工性等に悪影響を及ぼすため，初 晶を微細化する方策が必要である5).

最近，著者らは，Al 溶湯と過包晶 $\mathrm{Al}-\mathrm{Cr}$ 合金溶湯とを攪 拌混合することにより微細な金属間化合物を含む半凝固スラ リーを製造し，これを遠心鋳造する二段プロセスを試み，管 状のアルミニウム合金鋳物の外周表面に微細な金属間化合物 を集中分布させることに成功した6).

本プロセスのスラリー製造工程に扔いて使用される二種類 の溶湯のうち，Al 溶湯のように相対的に液相線温度の低い 溶湯を 1 次溶湯, 液相線温度の高い過共晶ないし過包晶の $\mathrm{Al}$-遷移金属合金溶湯を 2 次溶湯と称する。本工程では，2 次溶湯は, 混合容器内の 1 次溶湯の温度が低下した段階で 攪拌混合されることにより，低温の 1 次溶湯と接触して急 冷され(混合急冷効果7,8) , 微細な初晶金属間化合物を多数 晶出する．そして，さらに攪汼が継続されることにより，微 細金属間化合物粒子が均一分散し, 混合合金全体がスラリー 状になる。ここでは，この手法を「攪拌混合急冷法 (Stir- 
(a)

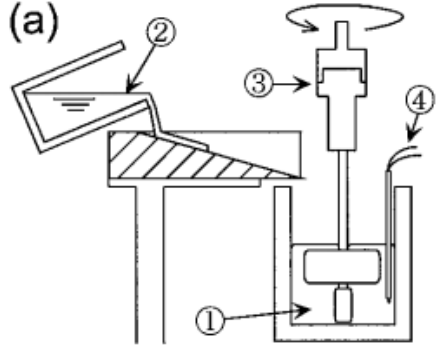

(b)

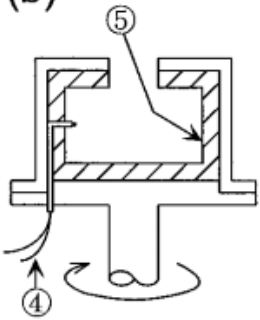

Fig. 1 Schematic illustration of the experimental apparatus. (a) Apparatus for sir-mix-quenching; (b) mold part of the vertical centrifugal caster. (1) first melt, (2) second melt, (3) stirrer, (4) thermocouple, (5) mold.

Mix-Quenching(6) )」と呼ぶことにする，なお，溶湯混合時 に打ける 1 次溶湯の状態としては，完全液相または半凝固 スラリーが考えられるが，半凝固スラリーを用いた研究例に ついても，既に著者らが過共晶 $\mathrm{Al}-\mathrm{Si}$ 合金の「スラリー・溶 湯混合法」と称して報告している ${ }^{9-12)}$.

過包晶組成の $\mathrm{Al}-\mathrm{Cr}$ 合金では最終凝固の反応型が包晶反 応 $\left(\text { 液相 }+\mathrm{Al}_{7} \mathrm{Cr} \rightarrow \mathrm{Al} \text { 固溶体 }\right)^{13)}$ であるため，マトリックスは $\alpha$ 相 (A1 固溶体) 単相になる.したがって，合金内の硬さ分 布は初晶金属間化合物粒子の分布状態によって規定される. これに対して，第三元素として例えば $\mathrm{Cu}$ を添加した合金で は， $\alpha$ 相の硬さの向上 ${ }^{14)}$ や $\theta$ 相 $\left(\mathrm{Al}_{2} \mathrm{Cu}\right)$ の晶出によって硬さ の分布や耐摩耗性が変化する可能性がある，そこで，本研究 では，攪拌混合急冷／遠心鋳造の二段プロセスによって $\mathrm{Al}$ $\mathrm{Cr}-\mathrm{Cu}$ 系鋳造管を作製し，その組織，硬さ，および耐摩耗 性を調查した。

\section{2. 実 験 方 法}

\section{1 摫拌混合急冷法}

Fig. 1(a)に，攪拌混合急冷法に用いた実験装置の模式図 を示す。この装置は, 摚拌装置と断熱れんが製の混合容器 (内径 $60 \mathrm{~mm}$, 深さ $85 \mathrm{~mm}$, 肉厚 $10 \mathrm{~mm}$ ) とから構成されて いる．混合容器内の合金の温度をモニタするために $\mathrm{K}$ 熱電 対を容器内壁近傍に設置した。また，攪拌子は直交する 2 枚のパドルを有している.

1 次溶湯には亜共晶組成の $\mathrm{Al}-4$ mass $\% \mathrm{Cu}$ 合金，また 2 次溶湯には過包晶組成の $\mathrm{Al}-10$ mass $\% \mathrm{Cr}$ 合金を使用した (以後，濃度単位の mass\%を\%と略記する)。1 次溶湯と 2 次溶湯との質量比は $3: 1$ とした。 このとき，混合後の平均 組成は $\mathrm{Al}-2.5 \% \mathrm{Cr}-3 \% \mathrm{Cu}$ となる。

Fig. 2 に, $\mathrm{Al}-\mathrm{Cr}-\mathrm{Cu}$ 系状態図の $\mathrm{Cr}$ 組成 $2.5 \%$ に抢ける縦 断面図 ${ }^{15)}$ を示す。これによると, $\mathrm{Al}-2.5 \% \mathrm{Cr}-3 \% \mathrm{Cu}$ 合金の 凝固過程で晶出し得るクロムアルミナイドとして $\gamma$ 相と $\beta$ 相とがあり，平衡凝固過程では，(1) $\mathrm{L}+\gamma$, (2) $\mathrm{L}+\gamma+\beta$, (3) $\mathrm{L}$ $+\beta$, (4) $\mathrm{L}+\beta+\alpha$, (5) $\beta+\alpha+\theta$, の順に相構成が推移する.た だし，凝固時に液相が過冷した場合は， $\beta$ 相が初晶として晶 出する可能性がある。これは過包晶組成の $\mathrm{Al}-\mathrm{Cr}$ 二元合金 においても同様であり，とりわけ攪拌混合急冷法では，2 次 溶湯は混合急冷効果により大きく過冷し，初晶 $\beta$ 相を晶出

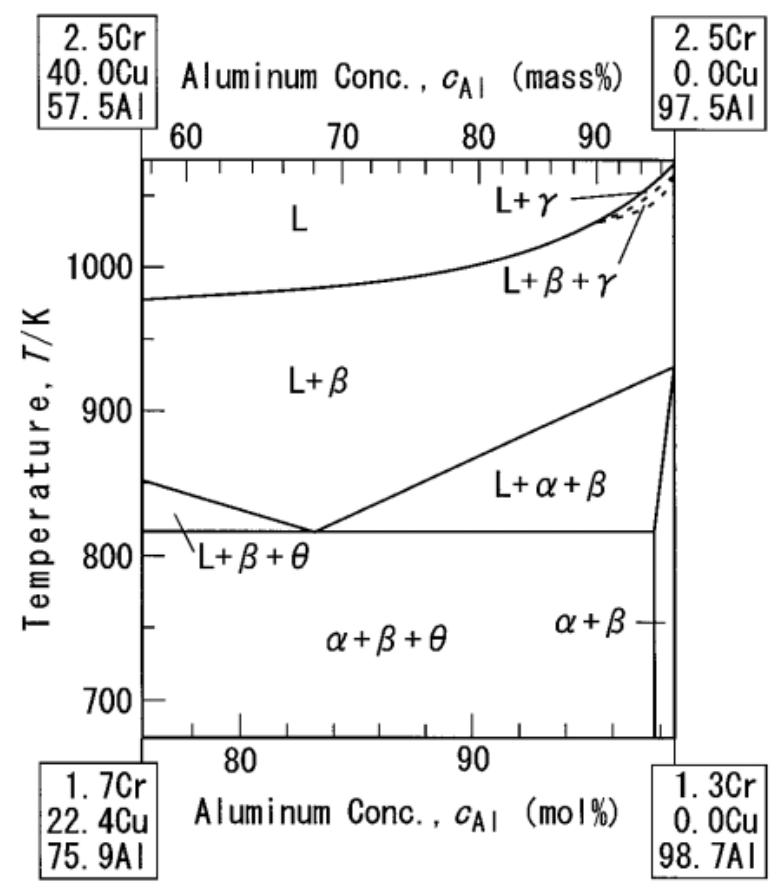

Fig. 2 Aluminum-side portion of the vertical cross section of the $\mathrm{Al}-\mathrm{Cr}-\mathrm{Cu}$ phase diagram at 2.5 mass $\% \mathrm{Cr}^{15)}$.

$\mathrm{L}$ : Liquid phase. $\alpha$ : Aluminum solid solution. $\beta: \mathrm{Al}_{7} \mathrm{Cr}^{13)}$ or $\mathrm{Al}_{45} \mathrm{Cr}_{7} \cdot \gamma: \mathrm{Al}_{11} \mathrm{Cr}_{2}{ }^{13)}$ or $\mathrm{Al}_{5} \mathrm{Cr} . \theta: \mathrm{Al}_{2} \mathrm{Cu}$.

するものと推測される，そこで，ここでは(1) (3)の領域で晶 出する $\beta$ 相と $\gamma$ 相とを一括して初晶金属間化合物と称する ことにする.

㩭拌混合急冷法の実験手順は, 以下の通りである.

最初に, 攪汼子を角速度 $4 \pi \mathrm{s}^{-1}$ で回転させながら過熱度 $100 \mathrm{~K}$ の 1 次溶湯を混合容器内に注湯し, 攪拌を加えながら 空冷した. 1 次溶湯の温度が液相線温度直上まで低下した時 点で，攪拌子の回転角速度を $12 \pi \mathrm{s}^{-1}$ まで上昇させ，直ちに 過熱度 $50 \mathrm{~K}$ の 2 次溶湯を混合した。その後, 攪拌を継続し ながら混合合金を空冷させ，所定の凝固段階に達した時点で 遠心鋳造した。

Fig. 3 に，攪拌混合急冷法単独の実験で得られた合金試料 の温度変化の例を示す．本研究では，Fig. 3 に示す(1)～(3)の 3 種類の凝固段階で遠心鋳造を行った。すなわち，(1)は $[\mathrm{L}+$ $\beta]$, (2) 抢よび(3)は $[\mathrm{L}+\beta+\alpha]$ であり, また, 最終的に晶出す る $\alpha$ 相の総量に対するスラリ一中の $\alpha$ 相の質量割合 $\left(f_{\alpha}\right)$ は，それぞれ，(1) $f_{\alpha}=0$, (2) $f_{\alpha}=0.035$, (3) $f_{\alpha}=0.085$ である.

\section{2 遠心鋳造}

Fig. 1(b)に, 本研究で使用した縦型遠心鋳造装置の鋳型 部の形状を示す。鋳型は断熱れんが製の円筒形容器 (内径 80 $\mathrm{mm}$ ·奥行き $40 \mathrm{~mm}$ ・肉厚 $10 \mathrm{~mm}$ ) である. 鋳型の回転角速 度 $(\omega)$ は $38 \pi \mathrm{s}^{-1}$ である.このとき, 試料外周での遠心力の 加速度は $59 \mathrm{G}$ となる。な扔，本実験では鋳型の予熱は行わ なかった．鋳型内での試料の冷却速度は攪拌混合急冷実験の 約 1.4 倍であった.

また，比較材として，通常の遠心鋳造法および複合鋳込反 遠心鋳造法 ${ }^{16-18)}$ による $\mathrm{Al}-2.5 \% \mathrm{Cr}-3 \% \mathrm{Cu}$ 合金の管状試料を 作製した．複合鋳込み遠心鋳造法は， 1 次溶湯と 2 次溶湯を 
回転鋳型中に時間差鋳造する手法であり, 鋳型内で溶湯混合 が行われる点に特徵がある.

通常遠心鋳造においては， $\mathrm{Al}-2.5 \% \mathrm{Cr}-3 \% \mathrm{Cu}$ 合金の溶湯 を過熱度 $100 \mathrm{~K}$ で鋳造した。 また, 複合鋳込み遠心鋳造で は，覺拌混合急冷法の場合と同じ溶湯の組み合わせを用い た。 たた， 1 次溶湯の鋳込みから 2 次溶湯の鋳込みまでの時 間間隔 $(\Delta \tau)$ を $125 \mathrm{~s}$ とした。既報16,17)の結果によると，複 合鋳込久遠心鋳造法では $\Delta \tau$ 值を調節して溶湯混合時の 1 次 溶湯を半凝固状態にすることにより，初晶金属間化合物の微 細化が促進される. 本研究で用いた条件は, 管状試料の長手 方向中央部に抢いて 1 次溶湯の凝固層が残存しない範囲で 最大の $\Delta \tau$ として予め求めたものである.

以上のいずれの実験においても，鋳造された合金の総質量 は約 $340 \mathrm{~g}$ であり，作製された管状試料の半径方向の厚さは 約 $16 \mathrm{~mm}$ である. 鋳造後, 試料の縦断面のマクロ組織を観

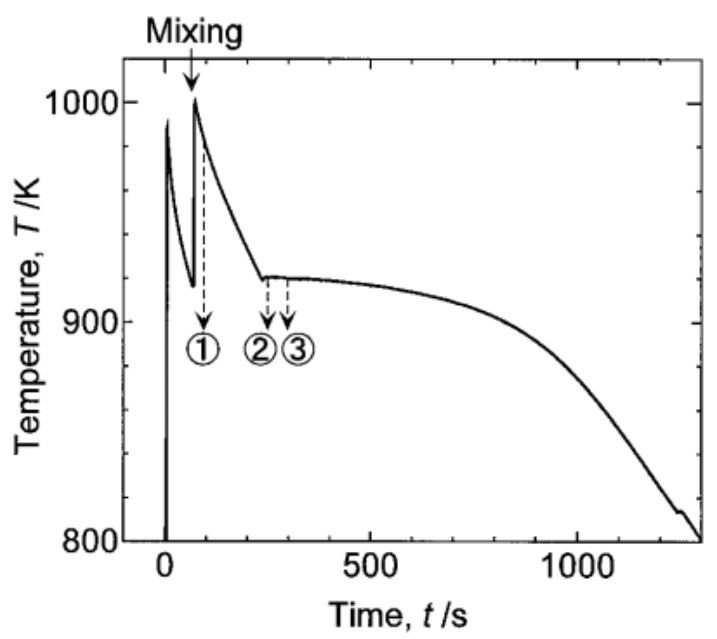

Fig. 3 Typical time-temperature curve measured during stirmix-quenching. Mass ratio of $\alpha$-phase in the mixed alloy slurry to the overall $\alpha$-phase to be crystallized in the alloy, $f_{\alpha}$, was (1) $f_{\alpha}$ $=0$, (2) $f_{\alpha}=0.035$ or (3) $f_{\alpha}=0.085$.
察するとともに，長手方向中央部近傍から試片を採取し， SEM の反射電子線像によるミクロ組織観察，ビッカース硬 さ測定，および摩耗試験を行った。摩耗試験ではピンオンデ ィスク式の摩耗試験機を用い, 摩擦の相手材 (ディスク)とし て FC20 鋳鉄を使用した. 試験片（ピン）は直径 $8 \mathrm{~mm}$ の円柱 形であり, 試料外周表面から約 $0.5 \mathrm{~mm}$ 内周側に研削した状 態で試験に供した。摩耗試験条件としては，摩擦速度を 1.9

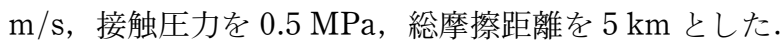

\section{3. 結果および考察}

\section{1 管状試料縦断面のマクロ組織}

Fig. 4 の (a) および (b)に，それぞれ通常遠心鋳造材および 複合鋳込み遠心鋳造材のマクロ組織を示す。また，(c)〜 (e) に攪挥混合急冷スラリーを用いた遠心鋳造材 (以後,「SMQ 遠心鋳造材」と称する)のマクロ組織を示す. Fig. 4(c)〜 (e) の各試料は，それぞれ Fig. 3 に示した(1)〜 (3)の凝固段階の スラリーを遠心鋳造したものである. Fig. 4 の試料のいずれ にも明度の異なる 3 種類の領域が観察される. 最も白い領 域は主として $\alpha$ 相から成る領域，灰色の領域は初晶金属間 化合物が存在する領域, また, 黒い斑点は気孔欠陥である.

Fig. 4 の試料の共通の特徵として，外周側に初晶金属間化 合物が集中分布した複合層が存在する。通常遠心鋳造材 (a) では，ミリオーダーにも及ぶ粗大な初晶金属間化合物が観察 される。これに対して，複合鋳込み遠心鋳造材 (b) 抢よび $\mathrm{SMQ}$ 遠心鋳造材 $(\mathrm{c}) \sim(\mathrm{e})$ の試料の初晶金属間化合物は，肉 眼では識別できないほど微細化されている.しかし, 複合層 の組織は試料によって異なっており，(b)の試料では，上部 外周側に 1 次溶湯凝固殼の一部が未溶解のまま残存してい る. また, SMQ 遠心鋳造の場合， $\alpha$ 相を含有したスラリー を使用した $(\mathrm{d})$ および $(\mathrm{e})$ の試料では, 粒状の $\alpha$ 相が複合層 内に観察される。また，スラリ一中の $\alpha$ 相晶出割合 $f_{\alpha}$ が増 加するほど, 複合層内に観察される粒状 $\alpha$ 相の割合が増加 すると共に, 複合層の厚さが増加する傾向が見られる. (a) No. 1

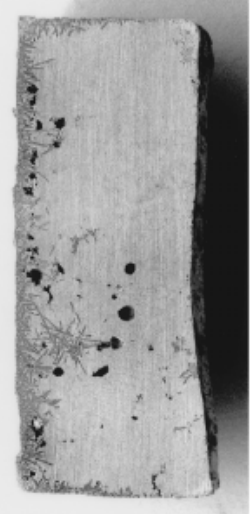

(b) No. 2

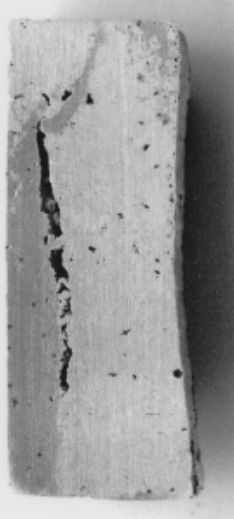

(c) No. 3

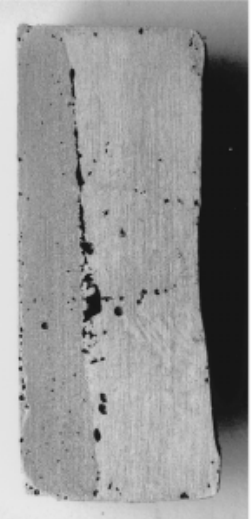

(d) No. 4

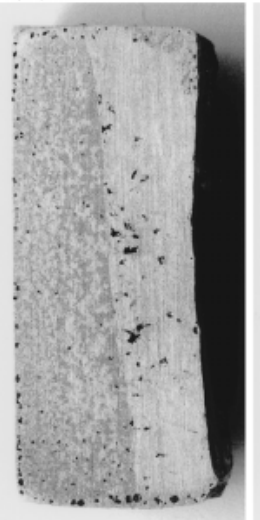

(e) No. 5

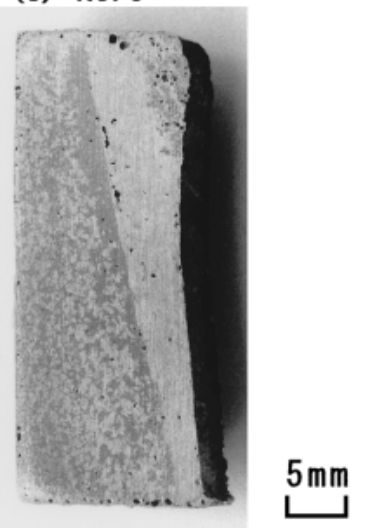

direction of centrifugal force

Fig. 4 Macrostructures showing the formation of the composite layer and pores in the tubular castings. Specimens : (a) No. 1 produced by the conventional centrifugal casting, (b) No. 2 produced by Centrifugal Duplex Casting, (c) No. 3 produced by the centrifugal casting of the mixed alloy slurry of $f_{\alpha}=0$, (d) No. 4 produced by the centrifugal casting of the slurry of $f_{\alpha}=0.035$, (e) No. 5 produced by the centrifugal casting of the slurry of $f_{\alpha}=0.085$. 


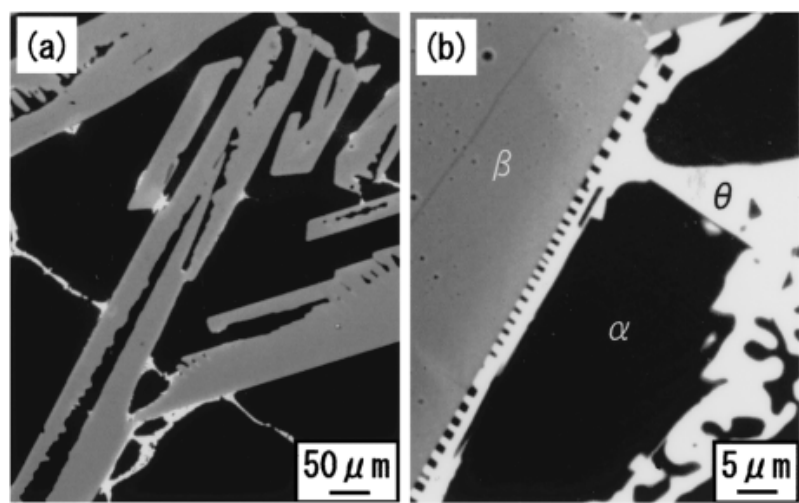

Fig. 5 Microstructures in the composite layer in the specimen No. 1 .

次に気孔欠陥について検討する。これらの気孔欠陥は，主 として複合層と内層との境界部に生成しており，とりわけ通 常遠心鋳造材 (a)，複合鋳込久遠心鋳造材 (b)， および $f_{\alpha}=0$ の SMQ 遠心鋳造材 (c)において顕著である.これに対し て，(c)〜 (e)の比較から明らかなように， $f_{\alpha}$ 值の大きな SMQ 遠心鋳造材ほど気孔欠陥が軽減する傾向がある。これ らの気孔欠陥をもたらした要因に関しては，以下のように考 えられる。

第一に，鋳型の熱吸収能が低い場合，試料内周表面からの 抜熱の影響が相対的に大きくなり，鋳物内部に最も凝固の遅 れる領域ができる19)。 また， $\mathrm{Al}-\mathrm{Cr}$ 二元系合金の試料6)では このような気孔欠陥が観察されなかったことから，Cu 添加 による影響が第二の要因として挙げられる。一般に $\mathrm{Al}-\mathrm{Cu}$ 系合金は広い凝固温度範囲を有するため，凝固収縮や吸収力゙ スに起因する気孔欠陥が生じやすいことが指摘されてい $る^{20)}$. 本研究の実験条件では, 以上の二つの要因が重なる ことによって気孔欠陷が生成しやすくなったものと考えられ る.したがって， $f_{\alpha}$ 值の大きい $\mathrm{SMQ}$ 遠心鋳造材の場合は， 予め粒状晶として晶出させる $\alpha$ 相の量を多くすることによ って，第二の要因を緩和するとともに，遠心分離効果により 外周側の液相率を減少させ，外周からの凝固の進行を容易に することによって，第一の要因を緩和することができたもの と推測される。

\section{2 複合層のミクロ組織}

Fig. $5(\mathrm{a})$ は，通常遠心鋳造材の複合層のミクロ組織であ る. 黒い領域が $\alpha$ 相, 灰色の領域が $\beta$ 相, 白い領域が $\theta$ 相 である。 $\theta$ 相の一部は $\beta$ 粒子に付着するように晶出してい る.この部分の拡大写真を Fig. 5 (b) に示す. 粗大な $\beta$ 粒子 の表面上に $\theta$ 相と $\alpha$ 相とが交互に晶出して規則的な幾何学 的パターンを形成している．この特異な組織の形成機構につ いては後で検討を加える.

Fig. 6 は，複合鋳込久遠心鋳造材抢よび SMQ 遠心鋳造材 に抢ける複合層のミクロ組織を示している。Fig. 6(a) は複 合鋳込み遠心鋳造材，また，(b)〜 (d)はそれぞれ Fig. 4 (c) 〜 (e)に示した SMQ 遠心鋳造材に対応している. Fig. 7 (a) 〜 (d) は，それぞれ Fig. 6(a)〜 (d)の拡大写真である.

まず，金属間化合物の分布という観点から Fig. 6 の各組
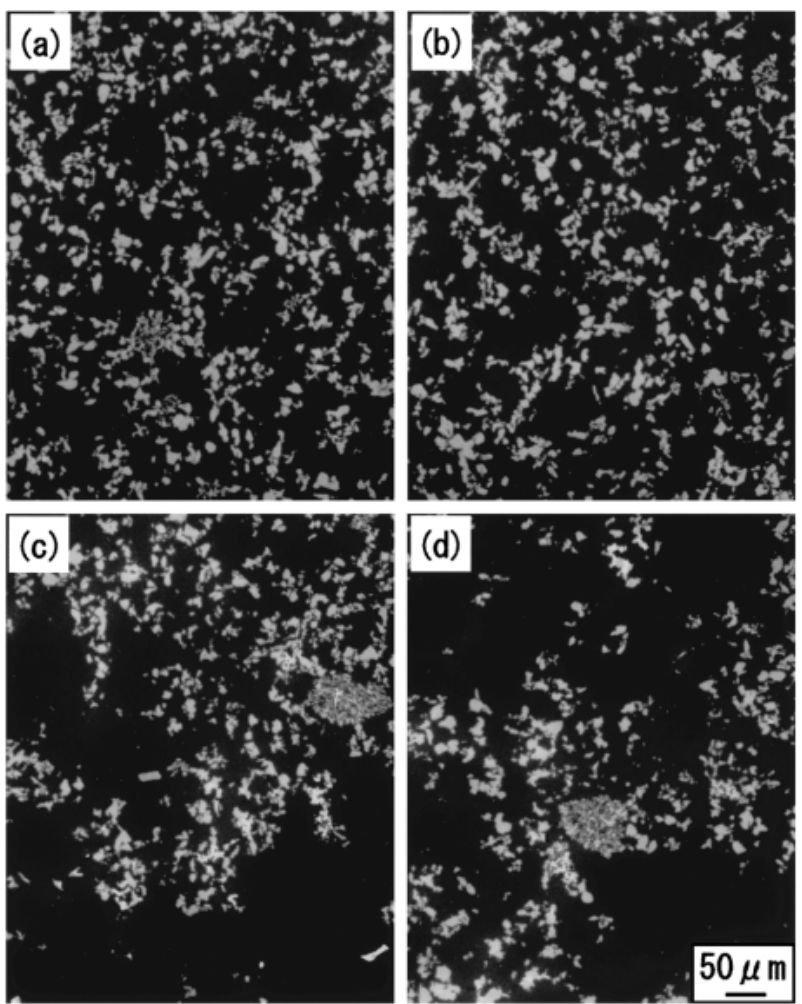

Fig. 6 Microstructures in the composite layer in the specimens No. 2 (a), No. 3 (b), No. 4 (c) and No. 5 (d).

織を比較する。（a）の複合鋳込み遠心鋳造材抢よび(b)の $\mathrm{SMQ}$ 遠心鋳造材 $\left(f_{\alpha}=0\right)$ を $10^{1} \sim 10^{2} \mu \mathrm{m}$ オーダーのスケー ルで観察すると, 初晶 $\beta$ 粒子が堆積する過程で互いに連係 することによって形成した海綿状の堆積構造 ${ }^{18)}$ が見られる ものの, $1 \mathrm{~mm}$ オーダー以上のスケールでは均一な分布とな っている.これに対して， $\alpha$ 相を含有したスラリーを遠心鋳 造した (c) 抢よび (d)では， $\alpha$ 粒状晶に相当する金属間化合物 空白領域が観察される。なお，例えば Fig. 6(d)に明瞭に見 られるように, 極めて微細な初晶粒子から成る島状の集団組 織が Fig. 6 の全ての試料で観察された。これは, 溶湯混合 過程で急冷された 2 次溶湯の流体塊が, 濃度的独立性を保 ったまま最終凝固に至ったものである16-18,21).

次に, Fig. 7 において各試料における $\theta$ 相の分布を比較す ると, 複合鋳込久遠心鋳造材 (a)では $\theta$ 相がほとんど観察さ れないのに対し，SMQ 遠心鋳造材 (b)〜 (d) では， $\theta$ 相が初 晶 $\beta$ 相の微細粒子を橋渡しするように晶出している. 後者 の傾向は， $\alpha$ 相を含有しないスラリーを遠心鋳造した $(\mathrm{b})$ よ りも， $\alpha$ 相を含有したスラリーを用いた $(\mathrm{c})$ 抢よび (d)の試料 の方がより顕著である. 複合層内の $\theta$ 相の晶出量が試料によ って異なる要因については, 以下のように考えられる.

まず，複合鋳込み遠心鋳造では， 1 次溶湯と 2 次溶湯との 混合は回転鋳型内で行われ, 2 次溶湯は濃度的独立性を比較 的保ったまま, 内部で初晶 $\beta$ 相を晶出しつつ鋳型外周側に 移動して複合層を形成する16,17)。したがって, 初晶 $\beta$ 粒子の 周囲の液相 $\mathrm{Cu}$ 濃度は相対的に低くなる。これに対して，覺 拌混合急冷スラリーでは液相中の $\mathrm{Cu}$ 濃度は均一であり，ま た， $\alpha$ 相の晶出量が多くなるほど液相 $\mathrm{Cu}$ 濃度は高くなる. 

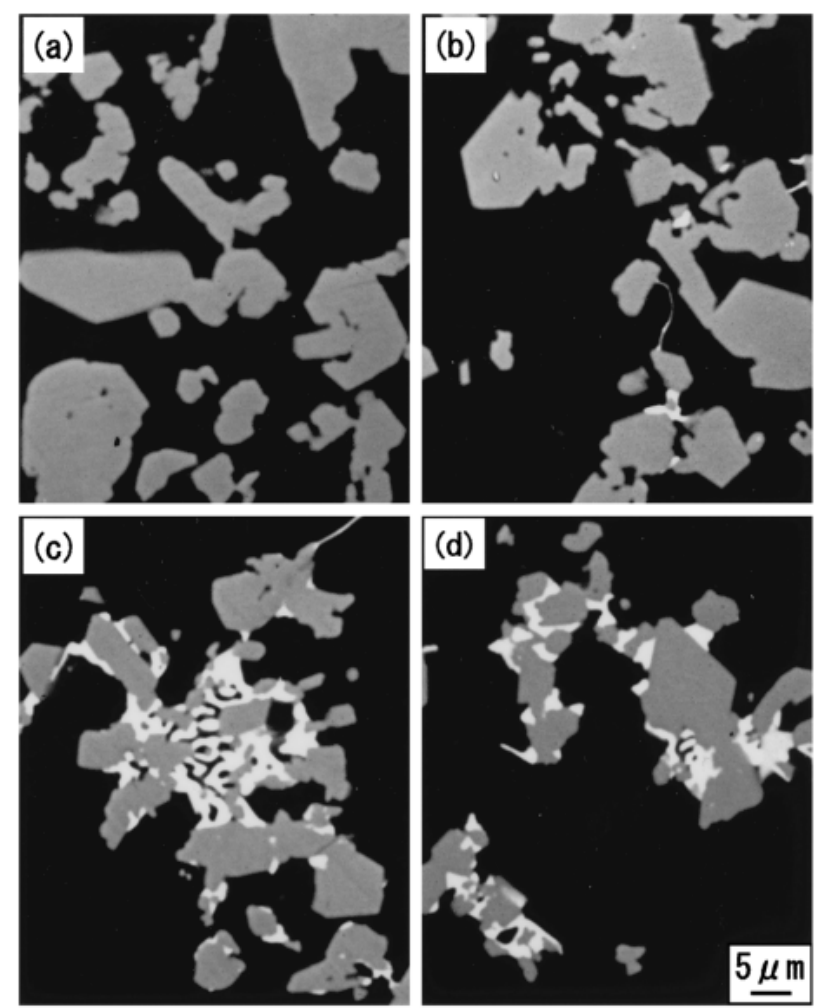

Fig. 7 Magnified images of the microstructures shown in Fig. 6. Specimens: (a) No. 2, (b) No. 3, (c) No. 4, (d) No. 5.

Fig. 7 (c), (d)の試料において $\theta$ 相の晶出が顕著なのはこの ためであると考えられる.

次に, SMQ 遠心鋳造材に見られる $\theta$ 相の特徵的な晶出挙 動を検討するために，攪汼混合急冷法単独の実験を行い，

Fig. 3 の(3)に対応する凝固段階でスラリーを水中急冷した試 料と，そのまま混合容器内で空冷凝固させた試料とを作製し た。それぞれの試料のミクロ組織を Fig. 8(a) 抢よび(b)に示 す. 水中急冷試料 (a)では, $\theta$ 相は初晶 $\beta$ 粒子の表面以外の $\alpha$ デンドライト間隙にも晶出している. Fig. 2 によると, $\theta$ 相の晶出する凝固反応は, $[\beta+\alpha+\theta]$ の 3 相が晶出する三元 共晶反応であるが， $\alpha$ デンドライト間隙の $\theta$ 相の近傍には共 晶 $\beta$ 相は観察されなかった。一方, 空冷凝固材では $\theta$ 相は もっぱら初晶 $\beta$ 粒子に付着した状態で晶出している。これ らの結果は, 三元共晶反応における共晶 $\beta$ 相の新たな核生 成が困難であることを示唆しており，溶質拡散のための時間 的余裕がある空冷凝固材の場合は, 初晶 $\beta$ 粒子の表面を基 盤として三相共存状態を実現する方が容易であったものと推 測される.Fig. 5(b)に示した通常遠心鋳造材の特異な組織 についても同様の要因により生成したものと推測される.

\section{3 管状試料外周表面近傍の硬さと耐摩耗性}

Fig. 9 にビッカース硬さ試験と摩耗試験の結果を示す．硬 さの值は, 外周表面から $1 \mathrm{~mm}$ 内周側の位置における 5 点 の測定値の平均值である. また, Fig. 9 で摩耗速度として示 したのは, 比摩耗量(単位荷重, 単位摩擦距離当たりの摩耗 体積)である.

Fig. 9 によると，通常遠心鋳造材 (No. 1) は硬さは最も高
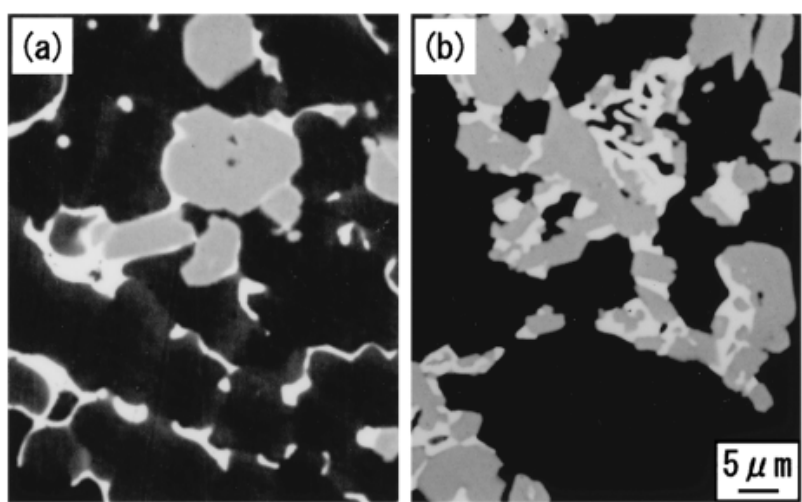

Fig. 8 Microstructures of the mixed alloy slurry of $f_{\alpha}=0.085$. (a) Water-quenched slurry (specimen No. 6). (b) Air-cooled slurry (specimen No. 7).

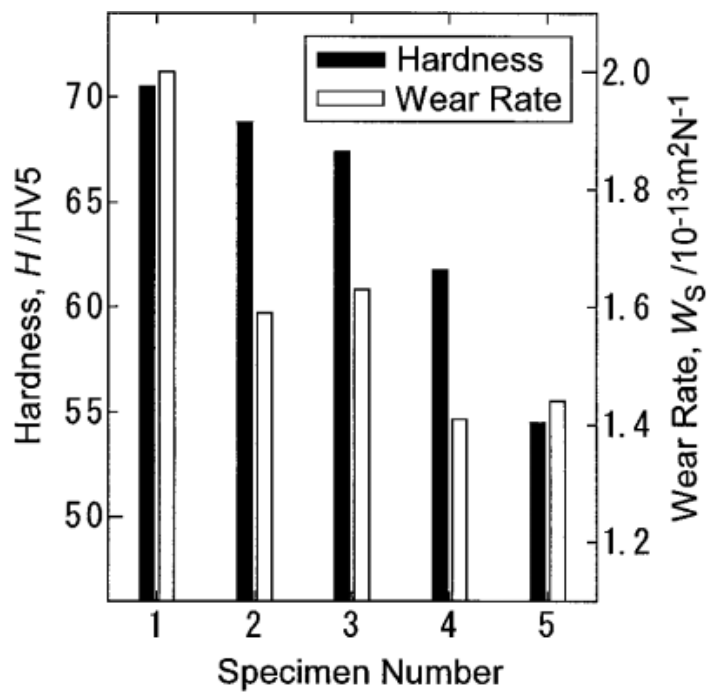

Fig. 9 Results of the hardness and the wear tests. The applied load in the hardness tests was $49 \mathrm{~N}$.

いが耐摩耗性は低い。本試料では, 摩耗試験途中(摩擦距離 $3 \mathrm{~km})$ で，粗大な初晶金属間化合物の破片が脱落して試料が 大きく欠損したため，この時点で試験を停止した．

一方，複合鋳込久遠心鋳造材 (No. 2) 抢よび $\mathrm{SMQ}$ 遠心鋳 造材 (No. 3〜5)では，硬さに関しては No. 2 およびNo. 3 が 高く, No. 5 が最も低い。この傾向は複合層内に打ける $\alpha$ 粒 状晶の存在割合に対応しており， $\alpha$ 粒状晶の割合が多くなる ほど硬さが低下する。

次に，耐摩耗性に関して Fig. 9 の結果を比較すると，No. 4 抢よびNo. 5 が最も耐摩耗性に優れており，硬さの傾向と は対応していないことが注目される，既報18)のように，Al$\mathrm{Cr}$ 二元系の複合鋳込久遠心鋳造材の場合，耐摩耗性は硬さ の増加に対応して向上する結果が得られているが，Fig. 9 の 結果はこれとは異なる傾向を示している。この原因につい て, 複合層に抢情 $\theta$ 相の晶出挙動という観点から考察を試 久る。

Fig. 10 は， $f_{\alpha}=0.085$ のスラリーから作製した SMQ 遠心 鋳造材 (No. 5) 抢よび同条件の攪拌混合急冷実験で作製した 水中急冷材 (No. 6) と空冷凝固材 (No. 7) について, $\alpha$ 粒状晶 


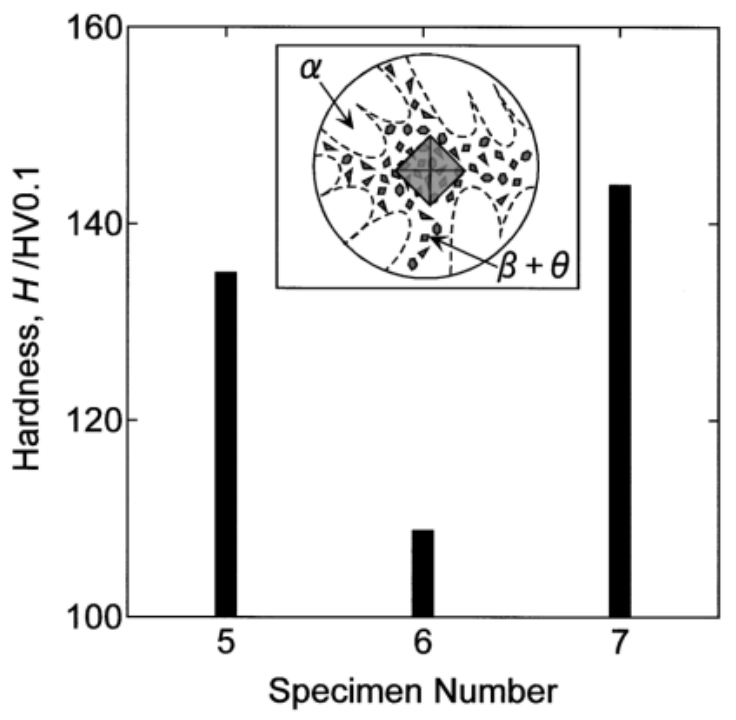

Fig. 10 Microhardness of the $\alpha-\beta-\theta$ coexisting area in the specimens No. 5, No. 6 and No. 7. The applied load in the microhardness tests was $0.98 \mathrm{~N}$.

(a) Isolated $\beta$-crystals

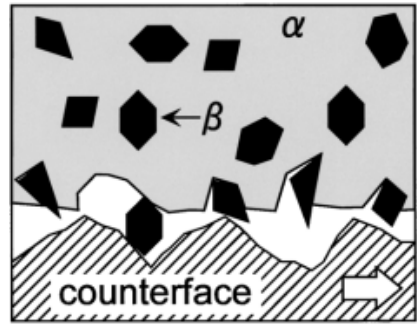

(b) Bonded $\beta$-crystals

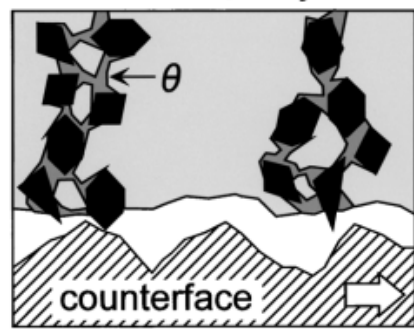

Fig. 11 Schematic illustration about the $\theta$-bonding effect on the wear behavior.

間隙の初晶 $\beta$ 粒子分布領域の微小硬さを測定した結果であ る.この結果から明らかなように，スラリーを急冷した場合 よりも徐冷した場合の方が高い硬さを示している。これは，

Fig. 7(d) および Fig. 8(b)に示したように， $\theta$ 相が初晶 $\beta$ 相 表面に優先的に晶出したことに起因すると考えられる.

硬質粒子分散型のアルミニウム基複合材料や過共晶 $\mathrm{Al}-\mathrm{Si}$ 合金に関する従来の研究 $22-24) に よ る と ，$ 硬質粒子の過度の 微細化は材料の耐摩耗性を低下させる傾向がある，この要因 としては，硬質粒子のサイズが小さすぎると，摩耗面に露出 した粒子が容易に脱落したり，摩耗面近傍のマトリックスの 塑性流動に抗しきれないことなどが挙げられる。したがって,

Fig. 11 に模式的に示すように, $\theta$ 相を介して微細な初晶 $\beta$ 粒子が強固に連係した組織を生成させることは，耐摩耗性の 向上に有効であると考えられる．このような観点から， $f_{\alpha}$ 值 の大きな SMQ 遠心鋳造材が硬さが低いにも関わらず良好な 耐摩耗性を示す理由を説明することができる.

\section{4. 結言}

攪拌混合急冷法で製造した半凝固スラリーを遠心鋳造する 二段プロセスにより $\mathrm{Al}-\mathrm{Cr}-\mathrm{Cu}$ 合金鋳造管 $(\mathrm{SMQ}$ 遠心鋳造
材）を作製し，その組織と，外周表面近傍における硬さおよ び耐摩耗性を調査し, 通常の遠心鋳造法および複合鋳込み遠 心鋳造法により作製した試料と比較した．得られた結果を以 下に要約する。

（1）いずれの試料でも外周側に初晶金属間化合物が集中分 布した複合層が存在する。初晶金属間化合物は，通常遠心鋳 造材では粗大に晶出するが，複合鋳込み遠心鋳造材および SMQ 遠心鋳造材では顕著に微細化される.

（2） SMQ 遠心鋳造材では，鋳造されたスラリー中の $\alpha$ 相 晶出割合 $\left(f_{\alpha}\right)$ の増加に伴い, 複合層内の粒状 $\alpha$ 相の割合お よび複合層の厚さが増加する.

（3） $\mathrm{Cu}$ の含有により，複合層と内層との境界部に気孔欠 陥が生成しやすくなる。しかし，SMQ 遠心鋳造材では $f_{\alpha}$ 值 を大きくすることにより気孔欠陷は軽減される。

（4） $\alpha$ 相含有スラリーを用いた試料では，複合層内に $\alpha$ 粒 状晶が存在するためマク口的硬さは低くなるが，耐摩耗性は 優れている。本試料では，微細な初晶 $\beta$ 粒子が $\theta$ 相を介し て強固に連係した組織が形成しており，これが耐摩耗性の向 上をもたらしたものと推測される.

文献

1) Y. Fukui, Y. Oya-Seimiya and K. Nakanishi: Trans. JSME A57 (1991) 1790-1793.

2) M. Mizuno, T. Matsuoka and T. Inoue: J. Soc. Sci., Japan 42 (1993) 1046-1051.

3) Y. Fukui, H. Yonekura, Y. Watanabe and K. Nakanishi: Trans. JSME A60 (1994) 1384-1389.

4) N. Yamanaka, Y. Watanabe, Y. Fukui and S. Nunomura: J. JILM 44 (1994) 330-335.

5) Y. Watanabe and Y. Fukui: J. JILM 46(1996) 395-403.

6) T. Ohmi, Y. Murota and M. Kudoh: Mater. Trans., JIM 40 (1999) 1063-1068.

7) T. Ohmi, K. Matsuura, M. Kudoh and Y. Itoh: J. JILM 48(1998) 42-47.

8) T. Ohmi, K. Matsuura, M. Kudoh and Y. Itoh: J. JILM 48(1998) 618-623.

9) T. Ohmi, K. Minoguchi, M. Kudoh, Y. Itoh, K. Matsuura and K. Ishii: J. Japan Inst. Metals 58(1994) 324-329.

10) T. Ohmi, K. Minoguchi, M. Kudoh, Y. Itoh and K. Matsuura: J. JILM 44(1994) 504-509.

11) T. Ohmi, K. Minoguchi, M. Kudoh, Y. Itoh and K. Matsuura: J. Japan Inst. Metals 58(1994) 1311-1317.

12) T. Ohmi and M. Kudoh: Materia Japan 37 (1998) 102-105.

13) J. L. Murray: Binary Alloy Phase Diagrams (2nd. Ed.), ed. by T. B. Massalski, (ASM, 1990) pp. 138-140.

14) T. Ohmi, K. Takahashi and M. Kudoh: J. Japan Inst. Metals 65 (2001) 1038-1044.

15) G. Petzow and G. Effenberg: Teranary Alloys (Vol. 4), (VCH, 1991) pp. 311-319.

16) T. Ohmi, Y. Kimura, Y. Itoh, M. Kudoh and K. Matsuura: J. Japan Inst. Metals 60 (1996) 490-496.

17) T. Ohmi, Y. Kimura, Y. Itoh, M. Kudoh and K. Matsuura: Mater. Trans., JIM 38(1997) 879-885.

18) T. Ohmi, Y. Kimura, Y. Itoh, K. Matsuura and M. Kudoh: J. Japan Inst. Metals 63 (1999) 429-434.

19) K. Murata, H. Harada, T. Nakata and T. Umeda: J. F. S. 66 (1994) 110-115

20) T. Takahashi and A. Kaimio: Casting and Solidification, ed. by JIM, (JIM, 1992) pp. 223-261.

21) T. Ohmi, M. Ueda and M. Kudoh: J. F. S. 69(1997) 822-827.

22) F. M. Hosking, F. Folgar Portillo, R. Wunderlin and R. Mehrabian: J. Mater. Sci. 17 (1982) 477-498.

23) T. Fujita, F. Kiyota, T. Hirano and Y. Kojima: J. JILM 37 (1987) 677-682.

24) T. Tanaka: J. JILM 42(1992) 161-167. 